University of Nebraska - Lincoln

DigitalCommons@University of Nebraska - Lincoln

USDA Forest Service / UNL Faculty Publications U.S. Department of Agriculture: Forest Service --

National Agroforestry Center

2012

\title{
Modelling approaches for relating effects of change in river flow to populations of Atlantic salmon and brown trout
}

J. D. Armstrong

Marine Scotland Science, John.Armstrong@scotland.gsi.gov.uk

K. H. Nislow

USDA Northern Research Station, knislow@fs.fed.us

Follow this and additional works at: https://digitalcommons.unl.edu/usdafsfacpub

Armstrong, J. D. and Nislow, K. H., "Modelling approaches for relating effects of change in river flow to populations of Atlantic salmon and brown trout" (2012). USDA Forest Service / UNL Faculty Publications. 229.

https://digitalcommons.unl.edu/usdafsfacpub/229

This Article is brought to you for free and open access by the U.S. Department of Agriculture: Forest Service -National Agroforestry Center at DigitalCommons@University of Nebraska - Lincoln. It has been accepted for inclusion in USDA Forest Service / UNL Faculty Publications by an authorized administrator of DigitalCommons@University of Nebraska - Lincoln. 


\title{
Modelling approaches for relating effects of change in river flow to populations of Atlantic salmon and brown trout
}

\author{
J. D. ARMSTRONG \\ Marine Scotland Science, Faskally, Pitlochry, Perthshire, UK
}

\author{
K. H. NISLOW
}

USDA Forest Service Northern Research Station, University of Massachusetts, Amherst, MA, USA

\begin{abstract}
Modelling approaches for relating discharge to the biology of Atlantic salmon, Salmo salar L., and brown trout, Salmo trutta L., growing in rivers are reviewed. Process-based and empirical models are set within a common framework of input of water flow and output of characteristics of fish, such as growth and survival, which relate directly to population dynamics. A continuum is envisaged incorporating various contributions of process and empirical structure as practical and appropriate to specific goals. This framework is compared with, and shown to differ from, approaches whose output is in the form of quantity and form of habitat (or usable area) based on its frequency of use by fish, which then is assumed to have some relationship with fish performance. A simple conceptual modelling approach is also developed to relate water flow to fish population characteristics to assess the likelihood of simple relationships between flow and usable area thresholds. Basic predictions of the model are tested against empirical data from a long-term individual-based study of juvenile $S$. salar and resident brook trout, Salvelinus fontinalis (Mitchell), in West Brook, Massachusetts. For this system, growth rates of both species increased linearly with flow during spring, summer and autumn months and bore no relation to $\mathrm{Q}_{95}$ or wetted-width discontinuities. Winter is identified as a season during which water might be abstracted most safely, but cautiously given sparse knowledge of wild salmonid fish at this time of year. These results, together with the fundamental conceptual problems inherent in usable area-based approaches, suggest that models that relate directly to fish performance outcomes may be more robust as a basis for flow prescriptions. However, this utility will depend strongly on our ability to generalise from a limited set of empirical studies and to use the results of these studies of management actions to inform and improve future models.
\end{abstract}

KEYWORDS: flow, habitat, PHABSIM, Salmo salar, Salmo trutta.

\section{Introduction}

Water resources are required for human needs, such as agricultural irrigation, for drinking and generation of hydropower. The question that then arises is how such modifications to the water resource can be balanced against impacts on the ecosystem or used to enhance habitats. It is crucial for managers of salmon, Salmo salar L., and trout, Salmo trutta L., to provide clear guidelines regarding discharge requirements for the fish, so that these needs can be taken into account.
There are two principle approaches that might by used to relate variation in habitat for fry and parr stages to fish populations: process-based models (e.g. Thorpe et al. 2004) and empirical models (e.g. Milner et al. 1998). Empirical models record population parameters, such as density and individual fish size, across a range of broad-scale inputs, such as variation in discharge. Process-based models seek to relate these inputs and outputs by the way of an understanding of the physical and biological functions of the system, with population-level consequences emerging from effects on these processes. A recent consideration of 
processes relating local habitat quality for $S$. salar and S. trutta to river discharge (Armstrong 2010) suggested a need for developing empirical and process-based models in tandem. Here this analysis is extended by considering how these two forms of models relate to one another for practical analyses of effects of discharge on salmonid populations.

At the same time, an alternative modelling approach involves relating changes in river flow to a measure of habitat area, with the assumption that this in turn will relate to fish performance (growth, survival and production). While this approach has been criticised on a number of different grounds (e.g. Gore \& Nestler 1988), its tractability has led to wide adoption by management agencies (Acreman et al. 2008). There is a real need, therefore, given the pace at which implementation of policies regarding flow prescriptions is being undertaken, to review the logical structure of this approach and to compare explicitly predictions between habitat use-based and fish performance-based models.

In particular, an important contemporary issue the relevance of $\mathrm{Q}_{95}$ and its relation to wetted stream width as a threshold in regulatory systems - is explored. $\mathrm{Q}_{95}$ represents the level of flow that is exceeded for $95 \%$ of the year. This level is adopted by the Environment Agency in England and Wales and by the Scottish Environment Protection Agency as a threshold below which special caution is adopted in abstracting water. Although the level may be applied for protection of the whole river community, the question arises as to how well it protects populations of S. salar and S. trutta.

\section{Population response model structures}

The basic features of the two main modelling approaches as categorised here are summarised in Fig. 1. Regardless of the form of the model, it seems logical that the input parameter must be river discharge or some correlate of river discharge. Similarly, the model output must be of a form that can be related to the strength of salmonid population and/or the availability of fish to the fishery of interest. However, although full process-based and empirical models can have a common input and output, the intervening structure is quite different. A fully parameterised process model includes a sequence of mathematical functions describing changes in physical, thermal, biological habitats and responses of the subject species. All these details can be accommodated in an empirical model by a black box, representing ignorance.
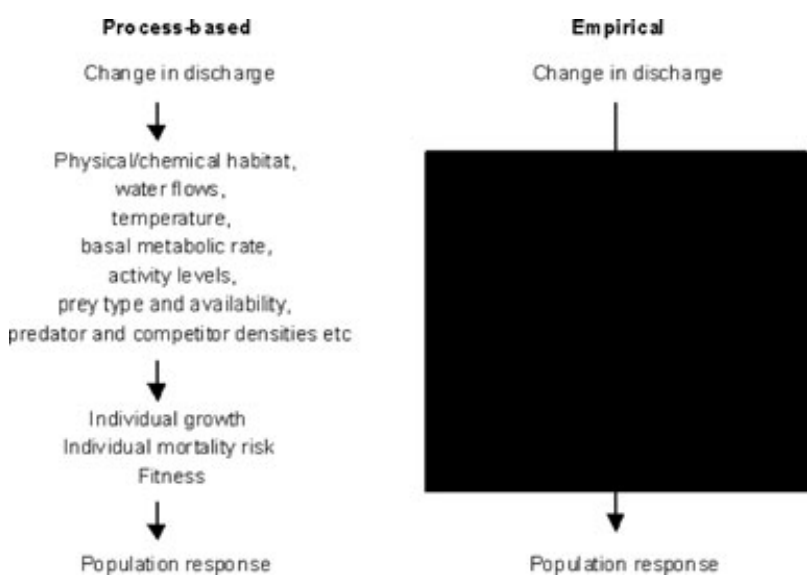

Figure 1. Comparison of pure empirical and process-based modelling approaches. Detailed understanding of the physico-chemical, thermal and biological processes is replaced by ignorance (represented as a black box) in empirical models. Process-based models may enable generality of predictions but may be unattainable except as hybrids with empirical components (see text for details).

\section{Empirical models}

The range of empirical observations relating discharge to $S$. salar and S. trutta populations is presented by Nislow and Armstrong (2012). A good example of the value of the approach is the correlation of S. trutta population parameters in Spanish Cantabrian rivers with seasonal variations in discharge (Lobón-Cerviá 2009). In this case, evidence suggested that discharge acted particularly on the early fry stage of the life cycle and hence provided a target for priority management action.

\section{Process-based models}

In principle, the physical habitat structure, fish energetics and community dynamics, in terms of variations in prey, predators, and competitors, can be integrated into the growth and mortality risk of each individual fish (Fig. 2a,b). In turn, the combination of growth and mortality risk determines the fitness of the fish in the sense of the chances of its genes being propagated in future generations (Fig. 2c) (Railsback \& Harvey 2002; Finstad et al. 2010). The combination of survivors at given times (for example, at smolt emigration) constitute the population-level terms, density, size distribution and variation in life-history strategy that relate directly to fisheries level quantities, such as catch rate.

Within this framework, it is possible to quantify, at least in concept, the values of patches of habitat in terms of the growth opportunities they present and, by 


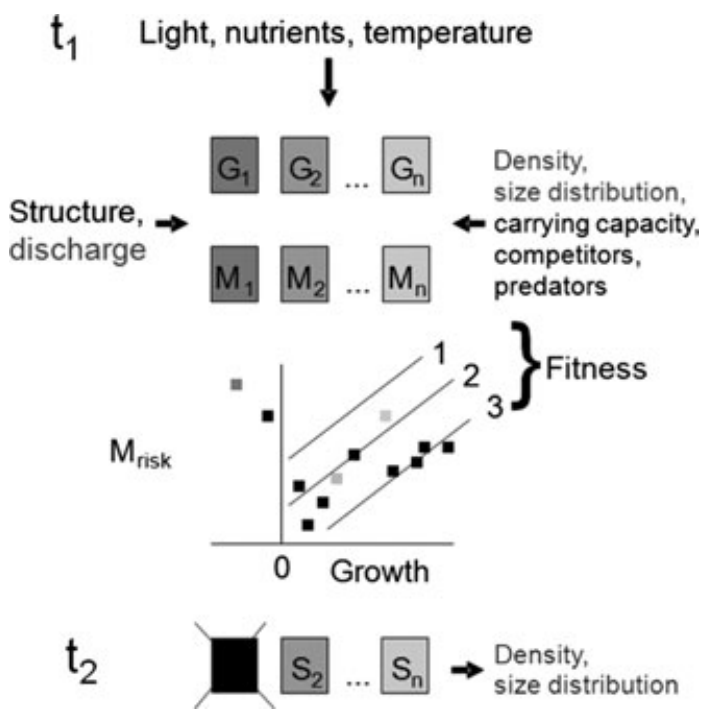

Figure 2. Principal factors relating discharge from time $t_{1}$ to $t_{2}$ with population at $t_{2}$. Coloured boxes represent individual fish $(1 \ldots n)$, which are influenced by the factors indicated by arrows, including water discharge, and exhibit growth (G) and experience mortality risk (M). Values of $\mathrm{G}$ and $\mathrm{M}$ may fall on a series of fitness contours, except that $\mathrm{M}$ may increase markedly as $\mathrm{G}$ approaches and decreases below zero. At time $t_{2}$, some fish have perished (indicated by black box and cross) and others have grown. The standing stock is determined by final size (S) and number of fish and depends on environmental parameters.

integrating survival opportunities, the fitness (Fig. 3). The conceptual terms required for derivation of growth are well established using energy budget models, whereas it is more difficult to estimate local mortality risk. Nevertheless, rules of thumb or tests in which fish can choose among habitat options can provide some insights into mortality risk (Armstrong 2010). Variation in discharge influences basic local parameters that drive energy budgets, such as flow rate, food delivery and temperature. Such factors can be incorporated within the model structure using, for example, classic understanding (Brett \& Glass 1973; Brett \& Groves 1979) of salmonid energetics, with adjustments for individual species and life stage. Ideally, fitness-based models would include variations with habitat in the interactions among predators and competitors and would relate standing stocks of fish to carrying capacity at size (Nislow \& Armstrong 2012). Obviously, the time course of change in flows is important, because temporary depletion of water may be tolerated by fish, whereas longer-term depletion may not.

The process-based approach has probably been most completely applied by Railsback and Harvey (2002) for populations of rainbow trout, Oncorhynchus mykiss (Walbaum), in the Pacific western US. The practical

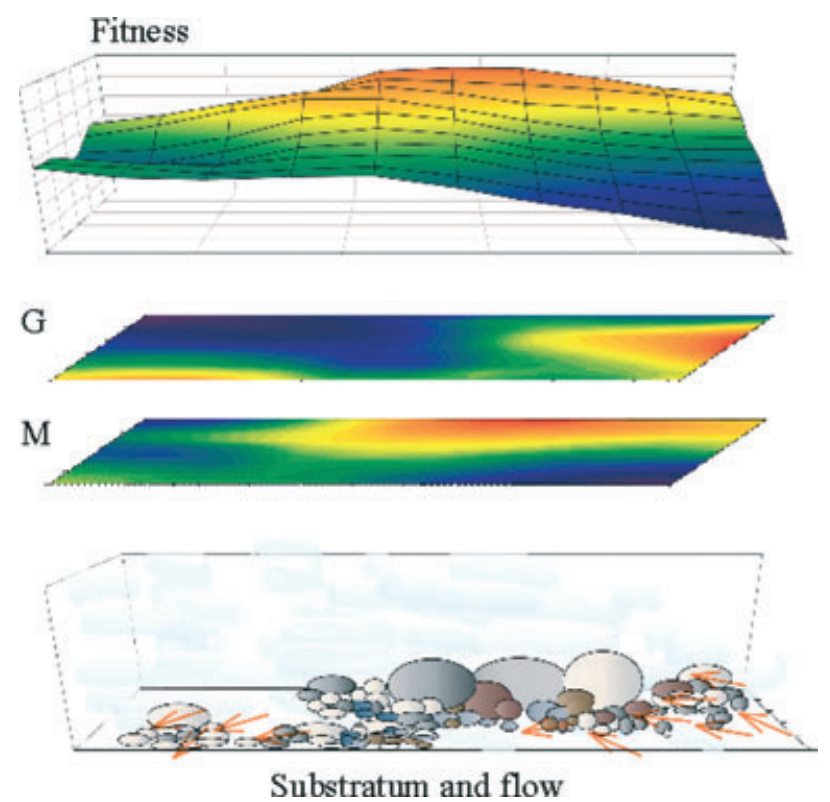

Figure 3. Representation of how local variations in water flow and substratum (lower frame) influence survival probability $(\mathrm{M})$ and growth opportunities $(\mathrm{G})$ for salmon and trout occupying the space; $\mathrm{G}$ and $\mathrm{M}$ combine as fitness (see text for details). High levels are denoted by orange-red, low levels by blue and intermediate values by green, as shown also by the vertical scale for fitness.

application of process-based models for $S$. salar and $S$. trutta has been constrained to only components of the overall system relating river discharge to ultimate fisheries catch. Nislow et al. (1999) modelled food intake as a function of water flow and used the relationship to predict distribution and growth of juvenile $S$. salar (Nislow et al. 2000, 2004). Bioenergetics models have been applied to explain distributions of fish (Fausch 1984; Guensch et al. 2001; Booker et al. 2004) to predict energy balance (Rincón \& Lobón-Cerviá 1993; Hayes et al. 2000) and to contrast niche breadths of $S$. salar and S. trutta (Armstrong 2010).

There are two distinctly different ways to apply fitnessbased models. First, by using a space-based approach, quantifying the local fitness value of the landscape (Fig. 2), the overall change in value of a river reach might be plotted against discharge by integration. This approach requires no information specifically on the fish within the reach. Secondly, using a fish-based approach, a fitness value can be ascribed to the locations that are used by each fish across a range of discharges.

\section{The process-empirical continuum of population models}

In practice, it is inconceivable that the vast complexity of the habitat occupied by $S$. salar and S. trutta 
(Armstrong et al. 2003) could be fully parameterised in the near future, if ever. Instead, much of the process detail must be approximation, assumption, black box or empirical extrapolation. Even if was it possible to describe fully the size distribution and numbers of $S$. salar smolts by process-based models, an extrapolation to fisheries catches would at present require resorting to empirical relationships between numbers of smolts and returning adults (Jonsson et al. 1998). Hence, there is a continuum of model structures relating discharge and key processes to salmonid populations and fisheries, with greater or lesser empirical and process components.

\section{Alternative structures}

Hitherto, models that have common inputs and outputs relating to fish population parameters as a logically robust structure have been considered. However, this classification omits a widely applied group of models, typified by PHABSIM (Bovee 1986), that have frequency of habitat use by fish as an input, and a parameter termed weighted usable area (WUA) as an output. This approach incorporates elements of empirical observations and assumption about behavioural processes of fish. Henceforth, references to PHABSIM will apply to models with similar structures.

\section{Preference-based process-empirical hybrid models}

PHABSIM comprises physical and biological components. The physical component relates local river-bed landscapes, in terms of parameters such as georeferenced distributions of velocity, depth and roughness to discharge. This component may be achieved by a range of models of various complexities (e.g. Williams 2010). The biological component relies on the observations of habitats used by individual fish, either from the study site or from other areas completely. The idea is that at one discharge, the abundance of each combination of habitat category is expressed as a proportion of total habitat (for example, one combination might be at depth of $20-25 \mathrm{~cm}$, velocity of $35-40 \mathrm{~cm} \mathrm{~s}^{-1}$, boulder substrate). The distribution of subject fish is also observed at this discharge; an index is generated which describes how much the relative usage of each combination of categories differs from its relative availability. These data are combined across variation in the values of the categories to generate a so-called preference curve or surface. Similarly, preference curves may be expressed as continuous variables. In some cases, preference curves may be transported from other studies or derived from expert opinion. The preferences are combined with availabilities of category combination and are integrated to provide WUA at the discharge. Hydraulic models then derive the distribution of local velocity, depth and roughness across a range of discharges of interest, and the preference indices are used to predict WUAs at these discharges.

\section{Meaning of WUA}

To bring PHABSIM into the scheme of logical model construction (Fig. 2) requires an understanding of how WUA relates to population parameters, such as density, size, growth and mortality. Unfortunately, the relationship between WUA and population parameters is obscure because habitat suitability (more correctly use) does not capture fitness value of habitat types (Rosenfeld 2003). This is exemplified by Holm et al.'s (2001) demonstration of very large differences in habitat suitability curves of young $S$. salar at different discharges under controlled conditions resulting in large discrepancies between predicted and measured WUA.

PHABSIM includes three assumptions regarding the biology of fish. First, that local abundance reflects local habitat quality; second, that preference is constant across discharges and third, that fish are free to move in response to change in habitat with discharge. Each of these assumptions may be invalid (Armstrong 2010). Indeed, a conceptual modelling analysis from first principles (Railsback et al. 2003) suggests that the basic structure of PHABSIM is flawed. Furthermore, the indeterminacy of scale in application of the approach leads to additional serious problems because of the very importance of scale in defining local habitat use. For a given spatial distribution of fish, a particular habitat type or habitat condition can be scored as preferred, neutral preference, or negative preference as a function of the scale at which habitat and fish abundance is measured (Folt et al. 1998). An area of particular debate is whether preference curves adequately capture habitat quality when applied to aggressive despotic animals such as salmonids. In these species, dominant individuals can monopolise preferred habitat with subordinate fish adopting a more passive cryptic foraging mode in habitat margins (Höjesjö et al. 2005) (Fig. 4). The higher numbers of subordinate fish will raise the preference scores of habitats that provide lower opportunities for survival and growth compared with habitats with fewer, but dominant and successful fish. In this situation, preference-based approaches will provide incorrect assessments of habitat quality. 


\section{Ideal despotic distribution}
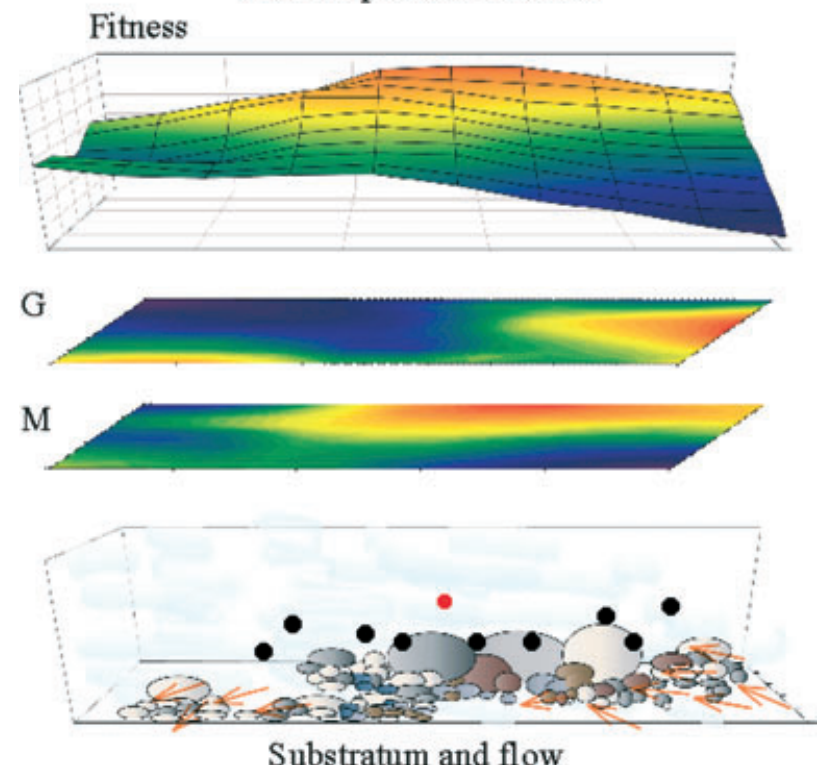

Figure 4. Illustration of the effect of despotic behaviour on habitat use. Fish (lower frame) are depicted by dots, the red dot represents a dominant despotic fish and black dots subordinate individuals. In this example, density is low in the best habitat, which is monopolised by the despot and high in intermediate habitat to which subordinate fish are marginalised. Details of the local variation in $\mathrm{M}, \mathrm{G}$ and fitness are provided in the legend to Fig. 3 .

In summary, doubts remain as to the value of PHABSIM, particularly regarding robustness of structure and relevance of outputs for broader management and population dynamics modelling frameworks.

\section{Basic conceptual model}

\section{The model}

Each modelling approach considered here has limitations. Processes cannot be fully quantified, whereas empirical response curves are not readily generalised and transferred to other river systems, and preferencebased approaches lack robust structure. Against this background, a basic conceptual model that provides a simple useful management tool is considered. This is particularly important because management methods have already been constructed that focus on specific flow levels, specifically $Q_{95}$, as a cut-off between levels of protection to fish stocks and as an extension, a nickpoint or discontinuity in the relationship between discharge and wetted area (Booker \& Acreman 2007). Is there a scientific basis for such an approach?

As discussed earlier, the value to the fish in a reach of stream of a given flow can be measured in terms of parameters that are relevant to the population. These include the number and size of spawners, the number and size of smolts, and in some cases, the number and size of intervening life stages. For example, a reach of shallow riffle habitat may be used almost exclusively by fry that then emigrate to deeper areas. There is not necessarily a direct proportional relationship between production of fry or parr and later life stages; it depends on local river habitat structure and population processes (Armstrong \& Nislow 2006). For simplicity, the term 'production' will be used to encapsulate the response of a conceptual population to change in discharge.

It is intuitive that production will tend to zero both at some low level of discharge, because water is needed to sustain life, and also at some high level of discharge, because fish cannot hold station and feed in torrents. Between these limits, production will peak at some level or range of levels of discharge at some critical component of the life cycle. The relationship between flow and production can be expected to vary with the physical structure of the river reach. As a simple example, in a V-shaped channel form, wetted width varies linearly with flow, whereas in the more common U-shaped channel form, wetted width decreases dramatically below a critical flow. Generally, reduction in wetted width results in reduction in the production of salmonid parr. However, there may also be a relationship between fish production and flow even when there is sufficient water to provide a full wetted width because increase in flow results in increase in mean local velocity and depth, which are both important habitat features (Armstrong et al. 2003).

In many cases, there may be a coincidence between the flow at which wetted width starts to decline sharply and $\mathrm{Q}_{95}$ (Booker \& Acreman 2007), depicted (Fig. 5) as the wetted-width nickpoint. The deficit in fish production that would occur by setting flow minima at the nickpoint is depicted by the difference between the production at this point and at a flow that would approach maximum levels (Fig. 5). The magnitude of this deficit depends critically on the shape of the flow production curve. For S. salar and S. trutta fry, which can thrive in shallow riffle habitats, it is plausible that production might be sustained at flows right down to the width nickpoint level so that no deficit would occur, although even these life stages may prefer faster deeper water (R. Kaspersson, J. Höjesjö \& J.D. Armstrong, unpublished). Other life history stages (such as adult $S$. trutta) often rely on deep water for shelter, or high microhabitat velocities that translate into high prey flux rates (Nislow et al. 2004). 


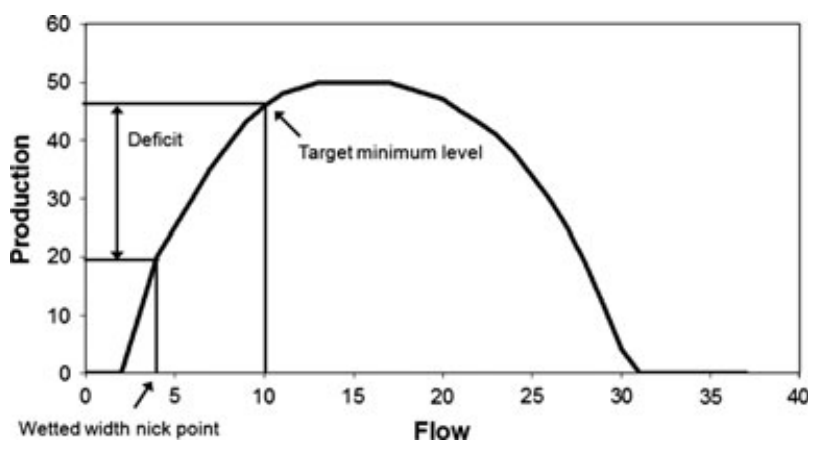

Figure 5. Conceptual relationship between production of salmonid fish and river flow. The target minimum flow illustrates a point at which a preferred production occurs (usually near maximum) and below which significant loss to production will occur. The flow at which the wetted-width nickpoint occurs (or $\mathrm{Q}_{95}$ ) is one option that has been favoured as a threshold for complete elimination of abstraction (handsoff flow). The difference between production at these two levels constitutes a deficit in production before full protection is provided. The gradient of the curve enables calculation of the loss because of fractional abstraction of a percentage of flow at any given discharge. Shape of the curve can be expected to vary locally.

Production of these fish in U-shaped channel forms would seem most likely to follow the relationship depicted in Fig. 5, where production potential would be negatively influenced by flow reduction above the wetted-width nickpoint, up to a peak. Small streams are likely to occupy space on the left limb of the curve, such that decrease in flow has a negative impact on production, whereas large rivers occupy space on the right of the curve, such that decrease in flow can have a positive effect on production.

\section{Testing the concept}

While this model derived from principles of established ecological mechanisms suggests potential direction and perhaps magnitude of effects, what data can be invoked to test the concept? Long-term studies are a potential source of information as they assess flow regime and fish response at relevant spatial and temporal scales. In a long-term study of $S$. trutta in a northern Spanish river (Lobón-Cerviá 2009), age-0 recruitment and subsequent cohort strength appear to follow the dome-shaped relationship described in Fig. 6. In this situation, flow could potentially be abstracted during high discharge years in spring without negative effects on populations. However, while no information on flood frequency or habitat area is given, it is not clear how these results can successfully inform flow prescriptions. Further, they pertain only to flows during a short period of time in

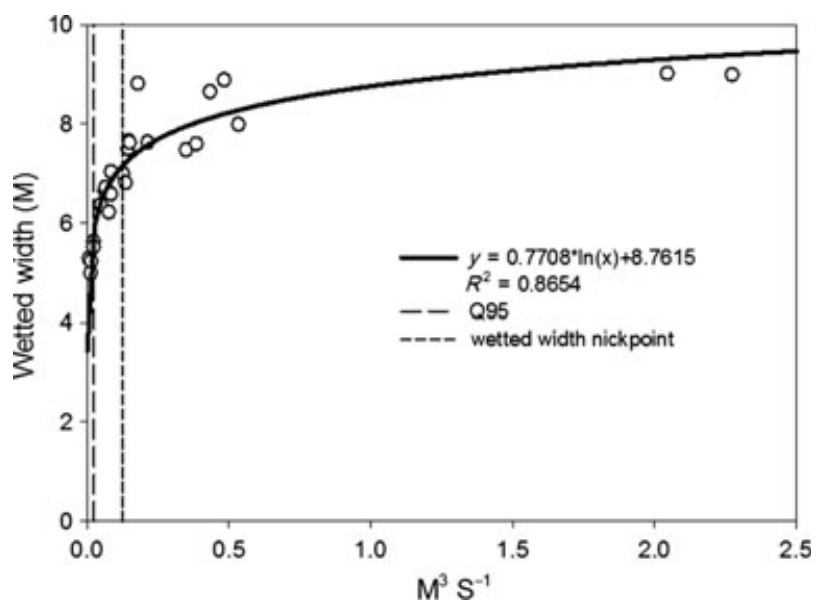

Figure 6. Empirical data from West Brook, Massachusetts, showing variation in wetted width with flow. The flow at which wetted width starts to change rapidly (derived by split regression analysis) is $100 \%$ higher than $\mathrm{Q}_{95}$, which is exceeded for $95 \%$ of the time. Regression model: parameters: wetted width $=15.16$ discharge +5.28 ; wetted width $=0.60$ discharge +7.80 .

spring and cannot inform flow management during the rest of the year.

In a long-term study of resident Salvelinus fontinalis and S. salar in West Brook, Massachusetts, seasonspecific flow-performance relationships were developed from individual fish-based data on growth, survival and movement for the entire juvenile life history from age- 0 in autumn through to adulthood or smolting (Xu et al. 2010a,b; Davidson et al. 2010). Discharge and wetted-width measurements were also made throughout the study, allowing calculation of flow production probabilities and description of the flow-wetted width relationship. Here these data are combined to relate biology of the fish to the river flow characteristics.

As predicted for U-shaped channels, a distinct nickpoint was observed in the flow-wetted width relationship (Fig. 6). The nickpoint, derived by split regression, was at a flow level substantially greater than the estimated $\mathrm{Q}_{95}\left(\sim 0.05 \mathrm{~m}^{3} \mathrm{~s}^{-1}\right)$. Effects of variation in flow were largely manifest in terms of differences in growth rates, which increased strongly and linearly with flow during spring, summer and autumn, and decreased with flow above a peak level (but with a much smaller magnitude of effect) during winter. Using these data, the change in growth potential (which is a major determinant of smolt age and population growth rate in anadromous salmonids, and a determinant of mortality risk and fecundity in resident salmonids; Milner et al. 2003) 
expected under different flow conditions can be estimated.

Results of these analyses have some important implications. First, there is reinforcement that $\mathbf{Q}_{95}$ does not necessarily equate with a threshold in wetted area but appears to be specific to local conditions. More importantly, however, it appears that substantial loss in growth potential occurs in both $S$. fontinalis and $S$. salar at flows well above $\mathrm{Q}_{95}$ and the wettedwidth nickpoint (Figs 6 and 7). For example, reduction in minimum and mean flow by one standard deviation from annual mean values reduced the size achieved by the average $1+S$. salar in autumn by 40 and $22 \%$ respectively. For size-dependent threshold traits (such as maturation and smolting), these effects will have a profound influence on population dynamics (Xu et al. 2010a,b). In terms of the conceptual model (Fig. 5), the flow rates recorded in this stream never extended beyond the ascending limb of the production response curve in spring, summer and autumn. Data for growth during winter fit well with the model, and in this season, production declines when flows exceeded a peak level.

\section{Discussion}

Consideration of complex process-based models is an important step in developing practical tools for relating discharge to populations because it forces an appreciation of the range of relevant physical, chemical and biological factors that vary. Here, the need to combine process-based and empirical models rather than viewing them as separate entities for application to management is illustrated. Furthermore, how these two categories of model can sit within the same logical structure is illustrated, and the appropriate input and output parameters as a first step in refining model choice and development is clarified.

It is apparent that no process-based model is likely to capture the full complexities of the systems that
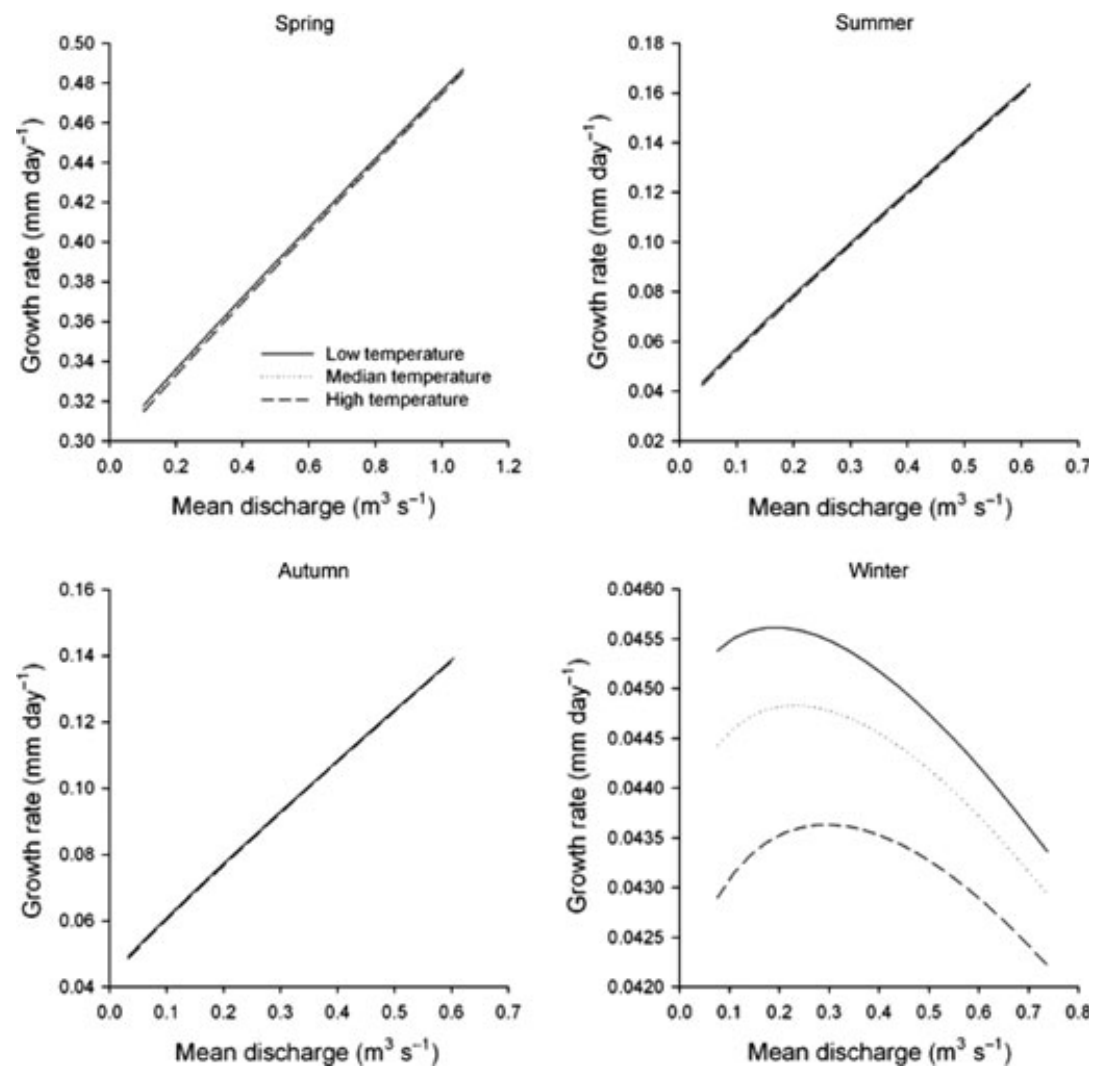

Figure 7. Relationships between growth of salmon and flow in four seasons in West Brook, MA. Graphs are derived from coefficients relating mean stream discharge (over a seasonal sampling interval) to growth rate over the same interval ( $n=8-9$ intervals) as components of a full empirical model growth parameterised by long term (10 years) of environmental and individual fish data (Davidson et al. 2010). Temperature has a significant effect only in winter. 
affect S. salar and S. trutta (Armstrong et al. 2003). However, application of such models has generally focussed on key processes that need to be understood to provide a meaningful level of predictive power. Railsback and Harvey (2002) applied individual-based modelling to relate local foraging and predation risk to chance of long-term survival. This detailed, but parameter sparse, approach was successful in predicting a range of population-level processes (Railsback \& Harvey 2002). Simple assessment of patch qualities in terms of variation in predicted foraging success with local water flow has had value in defining local habitat quality in natural rivers (Nislow et al. 1999, 2000, 2004). Furthermore, the very modelling process provides important insights and predictions in relation to variations between $S$. salar and $S$. trutta in susceptibility of change in flows, and highlights key parameters that need to be determined, such as change in overall levels of drifting invertebrates with discharge (Armstrong 2010).

A further important advantage of process-based models is their flexibility for incorporating covariates of change in discharge. For example, there is likely to be a broad range of potential changes in thermal regime that accompany variations in discharge, and associated temperature change can be incorporated in bioenergetics models using classic understanding (e.g. Brett \& Glass 1973; Brett \& Groves 1979) with adjustment for species-specific coefficients.

Empirical models can provide direct quantitative links between discharge and population parameters. Such data are extremely valuable but often very expensive to accrue (Nislow \& Armstrong 2012). These models can be derived by observation of one (or more) systems over time and then relating annual variations in flow to population parameters. Alternatively, they may capture spatial variation in discharge and populations. Much experience has been gained from relating the biology to spatial variations in habitat; meso-scale models, such as HABSCORE (Milner et al. 1998), can account for much variation within watersheds. However, such models generally transfer poorly to other regions (Fausch et al. 1988). This observation underpins a main constraint that empirical models cannot be used to extrapolate with confidence to circumstances in which conditions are substantially different from those that applied when the initial measurements were made.

Although PHABSIM has not found favour with many biologists, it is one of the most widely applied methods (Acreman et al. 2008). The physical description of variation in habitat with discharge, as developed in a component of PHABSIM, draws on the physical laws governing the interactions between flow, sediment and channel form, and appears logically robust. While these physical models are constrained by capacity to predict local responses to variation in discharge with sufficient accuracy, technical advances (such as 2-D hydraulic models; LeCler et al. 1994) have resulted in improvements and measurement efficiencies. Coupling the physical component of PHABSIM with estimates of habitat quality that are derived from fitness functions rather than fish distributions may have great value.

\section{Incorporating mechanisms, empirical models and management experiments in setting flow policy for salmonid rivers}

A wide range of studies, over a wide range of environmental contexts, provide information on flow-performance relationships, but with a considerable intrinsic level of uncertainty for any given application. Management will invariably be forced to act under this uncertainty. In an ideal world, the outcomes of management actions will in turn inform research and generate an adaptive management process. It has been argued (Walters 1997) that these management experiments, because they are conducted at appropriate scales, may have greater value than traditional small-scale observational or experimental studies.

As an example of how this process might work, if the evidence provided by the range of mechanistic and empirical studies is considered in a general life-history context (Nislow \& Armstrong 2011), a general case could be made that abstraction and storage of winter flows may be generally less detrimental to salmonid performance than would similar levels of abstraction in other seasons. An advantage of this recommendation is that, at least in parts of northern Europe and the north-eastern US, stream flows are frequently available for abstraction (in contrast to summer and autumn flows). Further, recent global climate models predict increases in winter precipitation and runoff for the UK and north-eastern North America, but corresponding decreases in spring and summer (Arnell 1999; Marshall \& Randhir 2008). Therefore, withdrawing water in winter for storage where possible seems a logical starting strategy. However, understanding of the winter ecology of streams and rivers is very limited, and detailed research and monitoring studies would be required to increase the understanding of the structure and function of salmonid rivers and refine water management methods.

The value of coupling sound conceptual models with empirical information is well illustrated by the data from West Brook. In broad terms, the analysis shows 
that expectations of the population responses of S. salar from first ecological principals were upheld, but also identified seasonal variations that provide a sound basis for developing management approaches. A next challenge is to develop the modelling tools to extrapolate beyond specific example sites to other locations. West Brook, and similar sites, provides an ideal situation in which to apply process-based modelling and high level empirical structures, in which, for example, stream type and geological structure are explanatory variables for the overall production-flow curves. The use of $\mathrm{Q}_{95}$ (or any particular flow percentile) as a general threshold value for management seems inappropriate because one would expect large among site variation in the relationship between $\mathrm{Q}_{95}$ and the amount of habitat that is suitable for salmonids. For example, in contrast to West Brook, in large fast-flowing rivers, peak production would be expected well below $\mathrm{Q}_{95}$ because only in very low flows would a large area of stream provide local water velocities sufficiently low to support juvenile $S$. salar and S. trutta. There is no evidence for a distinct threshold in effect of flow on salmonid populations at a distinct discharge level. Rather, it is likely that management of flow needs to accept that there is a progressive negative site-specific effect on fish populations of reducing water discharge across a broad range, and the cost of which must be offset against benefits of water use for other purposes.

\section{References}

Acreman M., Dunbar M., Hannaford J., Mountford O., Wood P., Holmes N. et al. (2008) Developing environmental standards for abstractions from UK rivers to implement the EU Water Framework Directive. Hydrological Sciences Journal 56, 1105-1120.

Armstrong J.D. (2010) Variation in habitat quality for driftfeeding Atlantic salmon and brown trout in relation to local water velocity and river discharge. In: P. Kemp \& D. Roberts (eds) Salmonid Fisheries: Freshwater Habitat Management. Oxford: Wiley-Blackwell, 1-27pp.

Armstrong J.D. \& Nislow K.H. (2006) Critical habitat during the transition from maternal provisioning in freshwater fishes, with emphasis on Atlantic salmon and brown trout. Journal of Zoology 269, 403-413.

Armstrong J.D., Kemp P.S., Kennedy G.J.A., Ladle M. \& Milner N.J. (2003) Habitat requirements of Atlantic salmon and brown trout in rivers and streams. Fisheries Research 62, 143-170.

Arnell N.W. (1999) The effect of climate change on hydrologic regimes in Europe: a continental perspective. Global Environmental Change 9, 5-23.
Booker D.J. \& Acreman M.C. (2007) Generalisation of physical habitat-discharge relationships. Hydrology and Earth System Sciences 11, 141-157.

Booker D.J., Dunbar M.J. \& Ibbotson A. (2004) Predicting juvenile salmonid drift-feeding habitat quality using a three-dimensional hydraulic-bioenergetic model. Ecological Modelling 177, 157-177.

Bovee K.D. (1986) Development and evaluation of habitat suitability criteria for use in the instream flow incremental methodology. US Department of the Interior, Washington: Instream Flow Information Paper 21, $235 \mathrm{pp}$.

Brett J.R. \& Glass N.R. (1973) Metabolic rates and critical swimming speeds of sockeye salmon (Oncorhynchus nerka) in relation to size and temperature. Journal of the Fisheries Research Board of Canada 30, 379-387.

Brett J.R. \& Groves T.D.D. (1979) Physiological Energetics. In: W.S. Hoar, D.J. Randall \& J.R. Brett (eds) Fish Physiology Volume VIII Bioenergetics and Growth. London: Academic Press, pp. 280-352.

Davidson R.S., Letcher B.H. \& Nislow K.H. (2010) Drivers of growth variation in juvenile Atlantic salmon (Salmo salar): an elasticity analysis approach. Journal of Animal Ecology 79, 1113-1121.

Fausch K.D. (1984) Profitable stream positions for salmonids: relating specific growth rate to net energy gain. Canadian Journal of Zoology 62, 441-451.

Fausch K.D., Hawkes C.L. \& Parsons M.B. (1988) Models that predict standing crops of stream fish from habitat variables 1950-1985. USDA Forestry Service General Technical Report, WO-213, 52pp.

Finstad A.G., Armstrong J.D. \& Nislow K.H. (2010) Freshwater habitat requirements of Atlantic salmon. In: Ø. Aas, S. Einum, A. Klemetsen \& J. Skurdal (eds) Atlantic Salmon Ecology. Oxford, UK: Wiley-Blackwell.

Folt C.L., Nislow K.H. \& Power M.E. (1998) Implications of temporal and spatial scale for Atlantic salmon (Salmo salar) research. Canadian Journal of Fisheries and Aquatic Research 55(Suppl. 1), 9-21.

Gore J.A. \& Nestler J.M. (1988) Instream flow studies in perspective. Regulated Rivers 2, 93-101.

Guensch G.R., Hardy T.B. \& Addley R.C. (2001) Examining feeding strategies and position choice of drift-feeding salmonids using an individual-based, mechanistic foraging model. Canadian Journal of Fisheries and Aquatic Sciences 58, 446-457.

Hayes J.W., Strk J.D. \& Shearer K.A. (2000) Development and test of a whole- lifetime foraging and bioenergetics model for drift feeding brown trout. Transactions of the American Fisheries Society 125, 315-332.

Höjesjö J., Armstrong J.D. \& Griffiths S.W. (2005) Sneaky feeding by salmon in sympatry with dominant brown trout. Animal Behaviour 69, 1037-1041. 
Holm C.F., Armstrong J.D. \& Gilvear D.J. (2001) Investigating a major assumption of predictive instream habitat models: is water velocity preference of juvenile Atlantic salmon independent of discharge? Journal of Fish Biology 59, 1653-1666.

Jonsson N., Jonsson B. \& Hansen L.-P. (1998) The relative role of density-dependent and density independent survival in the life-cycle of Atlantic salmon Salmo salar. Journal of Animal Ecology 67, 751-762.

LeCler M., Boudreau P., Bechara J., Belzile L. \& Villeneuve D. (1994) A model of habitat dynamics applied to landlocked Atlantic salmon (Salmo-salar) juveniles of the Ashuapmushuan river (Quebec Canada). Bulletin Francais de la Pêche et de la Pisciculture 332, 11-32.

Lobón-Cerviá J. (2009) Why, when and how do fish populations decline, collapse and recover? The example of brown trout (Salmo trutta) in Rio Chaballos (northwestern Spain). Freshwater Biology 54, 1149-1162.

Marshall E. \& Randhir T. (2008) Effect of climate change on watershed system: a regional analysis. Climate Change $\mathbf{8 9}$, 263-280.

Milner N.J., Wyatt R.J. \& Broad K. (1998) HABSCOREapplications and future developments of related habitat models. Aquatic conservation - Marine and Freshwater Ecosystems 8, 633-644.

Milner N.J., Elliott J.M., Armstrong J.D., Gardiner R., Welton J.S. \& Ladle M. (2003) The natural control of salmon and trout populations in streams. Fisheries Research 62, 111-125.

Nislow K.H. \& Armstrong J.D. (2012) Towards a lifehistory-based management framework for the effects of flow on juvenile salmonids in streams and rivers. Fisheries Management and Ecology 19, 451-463.

Nislow K.H., Folt C.L. \& Parrish D.L. (1999) Favorable foraging locations for young Atlantic salmon: application to habitat and population restoration. Ecological Applications 9, 1085-1099.

Nislow K.H., Folt C.L. \& Parrish D.L. (2000) Spatially explicit bioenergetic analysis of habitat quality for age-0
Atlantic salmon. Transactions of the American Fisheries Society 129, 1067-1081.

Nislow K.H., Sepulveda A.J. \& Folt C.L. (2004) Mechanistic linkage of hydrologic regime to summer growth of age-0 Atlantic salmon. Transactions of the American Fisheries Society 133, 79-88.

Railsback S.F. \& Harvey B.C. (2002) Analysis of habitatselection rules using an individual-based model. Ecology 83, 1817-1830.

Railsback S.F., Stauffer H.B. \& Harvey B.C. (2003) What can habitat preference models tell us? Test of a virtual trout population. Ecological Applications 13, $1580-1594$.

Rincón P.A. \& Lobón-Cerviá J. (1993) Microhabitat use by stream-resident brown trout: bioenergetic consequences. Transactions of the American Fisheries Society 122, 575587.

Rosenfeld J. (2003) Assessing the habitat requirements of stream fishes: an overview and evaluation of different approaches. Transactions of the American Fisheries Society 132, 953-968.

Thorpe J.E., Mangel M., Metcalfe N.B. \& Huntingford F.A. (2004) Modelling the proximate basis of salmonid life history variation, with application to Atlantic salmon, Salmo salar L. Evolutionary Ecology 12, 581-599.

Walters C. (1997) Challenges in adaptive management of riparian and coastal ecosystems. Conservation Ecology [online] 1, 1. Available from the Internet. URL: http:// www.consecol.org/vol1/iss2/art1/

Williams J.G. (2010) Lost in space, the sequel: spatial sampling issues with 1-D PHABSIM. Rivers Research and Applications 26, 341-352.

Xu C., Letcher B.H. \& Nislow K.H. (2010a) Context-specific influence of water temperature on brook trout growth rates in the field. Freshwater Biology 55, 2253-2264.

Xu C., Letcher B.H. \& Nislow K.H. (2010b) Size-dependent survival of brook trout in summer: effects of water temperature and stream flow. Journal of Fish Biology 76, 2342-2369. 